\title{
Research on the Influencing Factors and Competitiveness of Chinese Provincial Skiing
}

\author{
Chunlin $\mathrm{Li}^{1, \mathrm{a}}$, Qiaokun $\mathrm{Kang}^{* 1, \mathrm{~b}}$, Xinxin $\mathrm{Wu}^{1, \mathrm{c}}$ \\ ${ }^{1}$ Department of Mathematics and Statistics Hebei University of Economics and Business, China
}

\begin{abstract}
Facing the new pattern of Chinese skiing industry, in order to analyze the skiing competitiveness of 20 key provinces, the index system was constructed. The index system was constructed for 10 variables from four dimensions: production factors, demand factorsperipheral support and enterprise competition. Through factor analysis, three main factors were extracted, including industry support, site core and ski demand conditions. Then score calculation and cluster analysis were carried out. The skiing competitiveness ranking and classification of these key provinces are obtained. On this basis, the feasibility suggestions for improving the competitiveness of skiing in our province are put forward to promote the further development of snow and ice sports.
\end{abstract}

\section{Introduction}

State Sport General Administration issued Development Plan of Snow Sports (2016-2025). The plan proposes that more than 50 million people will directly participate in snow sports, and 300 million people will participate in snow sports. Now is the preparation period for the 2022 Beijing Winter Olympics. In order to better achieve the planning objectives, it is necessary to study the current situation of residents' participation in skiing and the influencing factors.

Xiaolan Li analyzed the demand and resistance of ski industry transformation and upgrading under the background of Beijing 2022 Winter Olympic Games[1]. Haibo Ye pointed out that the hosting of the 2022 Winter Olympics will have a significant impact on the overall pattern of China's skiing tourism industry. With the increase of the number of ski resorts in North China, Northwest China, Southwest China and central and southern China, Northeast China will face certain competition[2]. Lu Wang constructed structural equation model to analyze the relationship between Heilongjiang ice snow tourism emotion and customer satisfaction[3]. Mona Mirehie pointed out that active participation in snow leisure activities can improve people's physical and mental health, especially among women. It is a positive psychological method to participate in ice and snow activities to obtain happiness[4]. Jennifer N. Whitehead discussed the factors influencing the participation of the youth of ethnic minorities in snow activities[5]. John C. Eun put forward some suggestions and opinions on how to avoid injuries caused by snow activities[6]. Tracey J.Dickson used descriptive statistics, chi square analysis, odds ratio and linear regression to analyze the trend of head injuries in snow activities at resorts in western
Canada during the decade 2008-2018[7]. Young-JooAhnl discussed the organization and work arrangement of the Winter Olympic Games over the years[8].

At present, there is a large amount of data and more indicators in the research of domestic skiing industry. Factor analysis can use a few variables to reflect the main information of the original variables. Cluster analysis can group and classify a large number of data to understand the internal structure of the data set.

In this paper, the number of ski resorts is more than 10 as the sampling standard. Referring to the data in the 2018 White Paper on Skiing Industry, 20 provinces are selected as the research samples. From the four dimensions of production factors, demand factors, peripheral support and enterprise competition, 10 indicators are selected for factor analysis. On this basis, cluster analysis is carried out to find out the same competitiveness level provinces. On this basis, the feasibility suggestions for improving the competitiveness of skiing in our province are put forward to promote the further development of snow and ice sports.

\section{Construct index system}

On the basis of previous research findings[9-11], combined the data in the 2018 White Paper on Skiing Industry, 20 provinces were selected as the research samples. Taking the number of ski resorts more than 10 as the sampling standard. Based on the four first level indicators of production factors, demand factors, peripheral support and enterprise competition, 10 variables are selected as secondary indicators. Table 1 shows the index system of urban skiing competitiveness.

\footnotetext{
azhuimengren2021@163.com

* Corresponding author: ${ }^{\mathrm{b}}$ kangqiaokun@163.com

c3108564706@qq.com
} 
Table1. index system of urb

\begin{tabular}{|c|c|}
\hline $\begin{array}{c}\text { Primary } \\
\text { Indicators }\end{array}$ & Secondary Indicators \\
\hline Production & Number of Cableways $\mathrm{X}_{1}$ \\
\cline { 2 - 2 } Factors & Number of Ski Resorts $\mathrm{X}_{2}$ \\
\hline \multirow{2}{*}{$\begin{array}{c}\text { Peripheral } \\
\text { Support }\end{array}$} & Traffic Convenience $\mathrm{X}_{3}$ \\
\cline { 2 - 2 } & Number of Accommodation Enterprises $\mathrm{X}_{4}$ \\
\cline { 2 - 2 } & Number of Catering Enterprises $\mathrm{X}_{5}$ \\
\hline \multirow{3}{*}{ Enterprise } & Number of Ski Resorts with a Fall of more than \\
Competition & 300 Meters $\mathrm{X}_{6}$ \\
\cline { 2 - 2 } & number of ski resorts with an area of more than \\
\hline \multirow{3}{*}{$\begin{array}{c}50 \text { hectares } \mathrm{X}_{7} \\
\text { Factors }\end{array}$} & Per capita disposable income $\mathrm{X}_{8}$ \\
\cline { 2 - 2 } & GDP $\mathrm{X}_{9}$ \\
\cline { 2 - 2 } & Number of Higher Education Students per \\
& 100000 Population $\mathrm{X}_{10}$ \\
\hline
\end{tabular}

In order to ensure the timeliness, authority and scientificity of the data, the research data are mainly selected from China Statistical Yearbook and 2018 White Paper on Skiing Industry. The data in $\mathrm{X}_{1}, \mathrm{X}_{2}, \mathrm{X}_{6}, \mathrm{X}_{7}$ are from 2018 White Paper on Skiing Industry. The data in $X_{4}, X_{5}, X_{8}, X_{9}, X_{10}$ are from China Statistical Yearbook. The data in $X_{3}$ are from the formula derivation. Transportation convenience $=($ railway mileage + highway mileage)/the total area of the region.

\section{Analysis process}

Using factor analysis to eliminate collinearity. Calculate the comprehensive score of 20 provinces skiing competitiveness and make a comprehensive ranking. Then, cluster analysis is carried out to find out the competitive regions at the same level among different provinces.

\subsection{Factor analysis}

According to the principle that the eigenvalue is greater than 1, the common factor is extracted. Calculation results are shown in Table 2. It can be seen from table 2 that the cumulative contribution rate of variance of the three factors is $79.783 \%$, which basically covers most of the information of the original variable. So try to select three factors as common factors. The contribution rate of the first principal factor was $32.697 \%$, the second principal factor was $32.242 \%$, and the third principal factor was $14.844 \%$.

Table2. Total Variance Explained

\begin{tabular}{|c|c|c|c|c|c|c|}
\hline \multirow{2}{*}{ Factor } & \multicolumn{3}{|c|}{$\begin{array}{c}\text { Extraction Sums of } \\
\text { Squared Loadings }\end{array}$} & \multicolumn{3}{c|}{$\begin{array}{c}\text { Rotation Sums of } \\
\text { Squared Loadings }\end{array}$} \\
\cline { 2 - 7 } & \multirow{3}{*}{ Total } & \% of Variance & Cumulative\% & Total & \% of Variance & Cumulative\% \\
\hline 1 & 4.667 & 46.670 & 46.670 & 3.270 & 32.697 & 32.697 \\
\hline 2 & 1.945 & 19.447 & 66.116 & 3.224 & 32.242 & 64.939 \\
\hline 3 & 1.367 & 13.667 & 79.783 & 1.484 & 14.844 & 79.783 \\
\hline
\end{tabular}

In order to better name and explain the 3 extracted principal factors, the maximum variance method is used to rotate the factor load matrix. Table 3 shows the rotated factor load matrix. The first main factor has a large load on the GDP, the number of catering enterprises, the number of accommodation enterprises and the traffic convenience. The first main factor mainly reflects the relevant information of the above variables. So the first main factor can be named "relevant industry support $\mathrm{F}_{1}$ ". Relevant industry support explained $32.697 \%$ of the original variable information. The second main factor has a large load on the number of ski resorts with a fall of more than 300 meters, the number of cableways, the number of ski resorts with an area of more than 50 hectares, and the number of ski resorts. The second main factor mainly reflects the relevant information of the above variables. Therefore, the second principal factor can be named "site core $\mathrm{F}_{2}$ ". Site core explained $32.242 \%$ of the original variable information. The third main factor has a large load on the number of students and per capita disposable income of higher education per 100000 population. The third main factor mainly reflects the relevant information of the above variables. Therefore, the third principal factor can be named "skiing demand condition $\mathrm{F}_{3}$ ". The skiing demand condition explained $14.844 \%$ of the original variable information.

Table3. Rotated Component Matrix

\begin{tabular}{|c|c|c|c|}
\hline \multirow{2}{*}{ Index } & \multicolumn{3}{|c|}{ Factor } \\
\cline { 2 - 4 } $\mathrm{X}_{9}$ & $\boldsymbol{1}$ & $\boldsymbol{2}$ & $\boldsymbol{3}$ \\
\hline $\mathrm{X}_{5}$ & 0.925 & 0.026 & 0.092 \\
\hline $\mathrm{X}_{4}$ & 0.893 & -0.306 & 0.094 \\
\hline $\mathrm{X}_{3}$ & 0.690 & -0.324 & -0.052 \\
\hline $\mathrm{X}_{6}$ & -0.266 & 0.901 & 0.012 \\
\hline $\mathrm{X}_{1}$ & -0.267 & 0.898 & 0.184 \\
\hline $\mathrm{X}_{7}$ & -0.074 & 0.867 & -0.155 \\
\hline $\mathrm{X}_{2}$ & -0.143 & 0.739 & 0.049 \\
\hline $\mathrm{X}_{10}$ & 0.167 & -0.181 & -0.894 \\
\hline $\mathrm{X}_{8}$ & 0.391 & -0.172 & 0.777 \\
\hline
\end{tabular}

Determine the three main factors: relevant industry support $F_{1}$, site core $F_{2}$, skiing demand condition $F_{3}$. Combined with the data in Table 2, taking the proportion of variance contribution rate of each main factor in the total variance contribution rate of three main factors as the weight. The comprehensive score of skiing competitiveness of provinces is obtained:

$F=\left(32.697 \times F_{1}+32.242 \times F_{2}+14.844 \times F_{3}\right) \div 79.783$ (1)

Table 4 shows the factor score, comprehensive score and ranking of provinces and cities are shown in. 
Table4. Regional ranking and cluster analysis results

\begin{tabular}{|c|c|c|c|c|c|c|c|c|c|}
\hline Province & $F_{1}$ Score & Rank & $\mathrm{F}_{2}$ Score & Rank & $F_{3}$ Score & Rank & Comprehensive Score & Rank & Cluster Result \\
\hline Hebei & 0.56246 & 6 & 2.7963 & 1 & -0.83431 & 17 & 1.21 & 1 & 1 \\
\hline Shandong & 1.70774 & 2 & 0.2715 & 5 & -0.12549 & 11 & 0.79 & 2 & 3 \\
\hline Jiangsu & 1.90746 & 1 & -0.206 & 10 & 0.354 & 8 & 0.76 & 3 & 3 \\
\hline Beijing & 0.57409 & 5 & -0.332 & 11 & 2.33304 & 1 & 0.54 & 4 & 2 \\
\hline Heilongjiang & -0.93495 & 17 & 1.7954 & 2 & 0.92703 & 4 & 0.51 & 5 & 1 \\
\hline Zhejiang & 1.29841 & 3 & -0.425 & 13 & 0.80813 & 5 & 0.51 & 6 & 3 \\
\hline Jilin & -0.74257 & 14 & 1.593 & 3 & 0.36149 & 7 & 0.41 & 7 & 1 \\
\hline Henan & 1.11355 & 4 & -0.161 & 9 & -1.54029 & 19 & 0.1 & 8 & 3 \\
\hline Hubei & 0.5584 & 7 & -0.632 & 15 & 0.07464 & 9 & -0.01 & 9 & 3 \\
\hline Shanxi & 0.26722 & 9 & -0.114 & 8 & -0.62416 & 15 & -0.05 & 10 & 3 \\
\hline Sichuan & 0.49527 & 8 & -0.509 & 14 & -0.29761 & 13 & -0.06 & 11 & 3 \\
\hline Liaoning & -0.68077 & 13 & -0.085 & 7 & 0.96007 & 3 & -0.13 & 12 & 2 \\
\hline Inner Mongolia & -1.10976 & 19 & 0.2683 & 6 & 0.72167 & 6 & -0.21 & 13 & 2 \\
\hline Chongqing & 0.10373 & 10 & -0.761 & 17 & -0.24731 & 12 & -0.31 & 14 & 3 \\
\hline Xinjiang & -0.90207 & 16 & 0.4848 & 4 & -1.28629 & 18 & -0.41 & 15 & 3 \\
\hline Shanxi & -0.65292 & 12 & -0.42 & 12 & -0.02043 & 10 & -0.44 & 16 & 3 \\
\hline Tianjin & -0.75893 & 15 & -0.967 & 19 & 1.28073 & 2 & -0.46 & 17 & 2 \\
\hline Guizhou & -0.29034 & 11 & -0.823 & 18 & -1.63636 & 20 & -0.76 & 18 & 3 \\
\hline Gansu & -1.10289 & 18 & -0.716 & 16 & -0.52209 & 14 & -0.84 & 19 & 3 \\
\hline Ningxia & -1.41313 & 20 & -1.057 & 20 & -0.68644 & 16 & -1.13 & 20 & 3 \\
\hline
\end{tabular}

\subsection{Cluster analysis}

On the basis of factor analysis, cluster analysis is carried out on the key provinces with the scores of relevant industry support, site core, skiing demand condition and comprehensive factor. The results are shown in Table 4 . The average values of relevant industry support factor, site core factor and skiing demand condition factor of these three cities are calculated respectively. Table 5 shows the summary results.

Table5. Summary of categories

\begin{tabular}{|c|c|c|c|}
\hline Ward Method & $F_{1}$ Score & $F_{2}$ Score & $F_{3}$ Score \\
\hline First Kind Mean & -0.3716867 & 2.0615578 & 0.1514018 \\
\hline Second Kind Mean & 0.9314725 & -0.3171369 & -0.1997618 \\
\hline Third Kind Mean & -0.7040800 & -0.4052865 & 0.1270988 \\
\hline Total Mean & 0.0000000 & 0.0000000 & 0.0000000 \\
\hline
\end{tabular}

In the first category, Hebei, Jilin and Heilongjiang are the most competitive provinces. The first type of urban site core factor score is the highest. Jilin and Heilongjiang belong to the three eastern provinces of China, which are rich in ice and snow resources. Make it a province with strong skiing competitiveness. Although Hebei has no unique advantages in temperature and ice and snow resources, and the ability of skiing demand conditions and related industry supporting factors is relatively weak, its strong core elements of the field make its comprehensive competitiveness leap to the forefront of the country. Especially in recent years, with the opportunity of 2022 Beijing Olympic Games and regional advantages, it has attracted a large number of consumers from Beijing, Tianjin and surrounding areas.

In the second category, Beijing, Liaoning, Inner Mongolia and Tianjin are competitive in skiing. The second type of cities scored the highest in the related industry support factors. Liaoning and Inner Mongolia belong to the northern region of China, with unique geographical advantages and rich ice and snow resources. However, the core of the site is weaker than Heilongjiang and Jilin, which makes them belong to the second category. Tianjin and Beijing are close to Hebei and have strong skiing demand conditions. Since the Winter Olympic Games were held, a number of high-end large-scale ski resorts have been built in Hebei to provide support for the nearby areas.

The third category is Shandong, Jiangsu, Zhejiang, Henan, Hubei, Sichuan, Shaanxi, Chongqing, Xinjiang, 
Shanxi, Guizhou, Gansu, Ningxia are weak competitive in skiing. There is a big gap with the first class provinces, and the market competitiveness is insufficient. These provinces are at a disadvantage in the core elements of the site, or do not have advantages in the supporting elements of related industries. Therefore, the comprehensive score of these provinces is not high. However, skiing demand in such areas has a strong momentum, which can promote the summer snow sports.

\section{Conclusion}

Taking 20 provinces as samples, this paper selects 10 indicators from four dimensions: production factors, demand factors, peripheral support and enterprise competition. Factor analysis obtains the comprehensive score ranking of skiing competitiveness of 20 provinces. Through cluster analysis, the same competitiveness level provinces are divided into three categories. The conclusions are as follows. First, Hebei ranks first in terms of comprehensive ranking, becoming the most competitive province. Second, as an old ski resort in China, Northeast China has obvious advantages in natural resources. However, the construction of ski brands and the allocation of related resources still need to be further improved. Third, the competitiveness of skiing in the central and western regions is weak and still has great development potential. We can carry out ice and snow activities according to local conditions, and strive to promote the summer snow activities.

\section{References}

1. Xiaolan Li and Junchang Kan (2018). "Study on Transformation and Upgrading of Chinese Skiing Industry under the Background of Beijing 2022 Winter Olympics." Sports Culture Guide(3): 82-86.

2. Haibo Ye and Ying Zhang (2015). "Research on Sustainable Development of Chinese Skiing Tourism Industry." China Winter Sports 37 (4): 88-92.

3. Lu Wang (2017). The Effect of Consumption Emotions on Customer Satisfaction in Snow and Ice Tourism of Heilongjiang Province, Harbin Institute of Technology. Ph.D.

4. Mona Mirehie and Heather J Gibson (2019). "Women's participation in snow-sports and sense of well-being: a positive psychology approach." Journal of Leisure Research.

5. Jennifer N. Whitehead (2019). Factors Influencing Racially Ethnic Minority Youth Participation in Snow Sports, Walden University. Ph.D.

6. John C. Eun and Michael Bronsert, et al. (2015). "Vascular Injury is Associated with Increased Mortality in Winter Sports Trauma." Annals of Vascular Surgery(29): 109-113.

7. Tracey J Dickson' and F AnneTerwiel (2020). "Head injury and helmet usage trends for alpine skiers and snowboarders in western Canada during the decade 2008-9 to 2017-18." Journal of Science and
Medicine in Sport: 1-16.

8. Young-JooAhn. Recruitment of volunteers connected with sports mega-events:A case study of the PyeongChang 2018 Olympic and Paralympic Winter Games [M].Journal of Destination Marketing\&Management, 2018 (8):194-203.

9. Peng Zhou (2018). The Theory and Practice of China's Tourism Economy(1978-2017). Zhejiang, Zhejiang People's Publishing House.

10. Sen Cheong Kon and L. W. Turner (2005). "Neural network forecasting of tourism demand." Tourism Economics 11 (3): 301-328. Study on Transformation and Upgrading of Chinese Skiing Industry under the Background of Beijing 2022 Winter Olympics.

11. Xin Li, R. L. (2020). "Network analysis of big data research in tourism." Tourism Management Perspectives 33: 1-12. 